\title{
Ensino Inclusivo: um breve olhar sobre a educação inclusiva, a cegueira, os recursos didáticos e a área de biologia
}

\section{Inclusive Education: a brief look on inclusive education, blindness, educational resources and the biological area}

\author{
Helena C. Castro ${ }^{1}$ \\ Lourena Marinho ${ }^{2}$ \\ Eloah C. L. Neri ${ }^{3}$ \\ Ruth Mariani ${ }^{4}$ \\ Cristina M. C. Delou ${ }^{5}$
}

\section{RESUMO}

A educação inclusiva defende a igualdade de ensino entre os indivíduos e conjuga diversas mudanças nas diretrizes educacionais, a fim de proporcionar oportunidades justas e amplas a todos. Atualmente, existe a sensibilização e o conhecimento sobre os alunos com necessidades especiais que devem ser obrigatoriamente atendidos, assim como todos os alunos regulares das escolas. Considerando que o entendimento de conceitos da área de Ciências da Natureza e Matemática e suas tecnologias apresentam significativa dificuldade, posto que naturalmente requeira uma capacidade de abstração significativa do aluno e/ou usa metodologias com extensivo acervo visual, o nosso objetivo foi realizar uma revisão teórica sobre a confecção de materiais didáticos inclusivos que tem como auxiliar o processo de ensino-aprendizagem dos alunos como um todo, incluindo aqueles com cegueira ou deficiência visual na compreensão das diferentes áreas de conhecimento incluindo a ciência e tecnologia. O trabalho foi realizado através de uma pesquisa teórica, na qual se privilegiou a ligação entre os critérios de atualidade e generalidade, procurando produzir uma reflexão sobre a produção dos recursos didáticos utilizados nas salas de aulas. As palavras chave inclusão, cegueira, recursos didáticos e biologia foram utlizados nos sites de busca Medline, Scielo, Portal Capes e Bireme. Os resultados encontrados mostram que os materiais didáticos táteis voltados para a inclusão de alunos com cegueira ou baixa visão são raros ou mesmo ausentes e ainda carecem da compreensão do contexto inclusivo, pois são, em sua maioria, exclusivos para estes alunos, o que não estimula ou mesmo evita a participação dos outros alunos durante o processo de aprendizagem, seja por falta de apelo visual ou por sua individualidade intrínseca. Os preceitos principais da inclusão que prediz a questão da participação do aluno com necessidade especial visual em sua própria comunidade escolar, o que não deve se limitar à partilha de espaços físicos comuns , mas também na busca da produção constante de materiais e métodos educativos inclusivos que possam facilitar o seu aprendizado. Palavras-chave: cegueira, educação inclusiva, recursos didáticos, ensino.

Palavras-chave: cegueira, educação inclusiva, recursos didáticos, ensino.

1 Programa de Pós-graduação em Ciências e Biotecnologia (PPBI), Instituto de Biologia, Universidade Federal Fluminense (UFF), Niterói, RJ.

2 Programa de Pós-graduação em Ciências e Biotecnologia (PPBI), Instituto de Biologia, Universidade Federal Fluminense (UFF), Niterói, RJ.

3 Programa de Pós-graduação em Ciências e Biotecnologia (PPBI), Instituto de Biologia, Universidade Federal Fluminense (UFF), Niterói, RJ.

4 Programa de Pós-graduação em Ciências e Biotecnologia (PPBI), Instituto de Biologia, Universidade Federal Fluminense (UFF), Niterói, RJ.

5 Laboratório de Antibióticos, Bioquímica, Ensino, e Modelagem Molecular (LABiEMol), Departamento de Biologia Celular e Molecular, Instituto de Biologia, Universidade Federal Fluminense (UFF), CEP.: 24210130, Niterói, RJ, Brazil. e-mail: cristinadelou@globo.com e hcastrorangel@yahoo.com.br. 


\section{ABSTRACT}

inclusive education advocates equality of teaching among individuals and combines several changes in educational guidelines in order to provide fair and ample opportunities to all. Currently, there is awareness and knowledge required to be met regarding students with special needs, as well as all children of regular school system. Considering that the understanding of concepts in the area of Sciences of Nature and Mathematics and their technologies present significant difficulty, since it naturally requires significant abstraction capacity from the student and / or the utilization of methodologies with extensive visual collection, our goal was to conduct a literature review on the making of inclusive teaching materials whose objective is complementing the teaching-learning process of students as a whole, together with those with visual impairment or blindness, in understanding the different fields of knowledge, including science and technology. The study was conducted through a theoretical research which favored the connection between the present time and general criteria, seeking to produce a reflection on the production of teaching resources used in the classroom. The keywords: inclusion, blindness, learning resources and biology were utilized in the sites Medline, SciELO, Capes Portal and Bireme. The results show that tactile teaching materials aimed at the inclusion of students with blindness or low vision are rare or even absent and still lack the understanding of inclusive context, since they are, for the most part, made exclusively for these students, which does not stimulate and even prevents participation of other students during the learning process, either for lack of visual appeal or for their intrinsic individuality. The main principles of inclusion, that predicts the issue of participation of students with special visual needs in their own school community, which should not be limited to the sharing of common physical spaces, but also to the pursuit of constant production of inclusive materials and educational methods that can facilitate their learning.

Keywords: blindness, inclusive education, teaching resources, teaching.

\section{INTRODUÇÃO}

\section{1 Educação Inclusiva: a essência}

Como princípio essencial da Educação inclusiva, todas as crianças tem o direito de pertencerem a uma mesma escola, aprendendo e participando das atividades em conjunto, à despeito de suas dificuldades e diversidades (BRASIL, 2007). De acordo com a Lei de Diretrizes e Bases da Educação Nacional, Lei nº 9.394/96 (BRASIL, 1996), as escolas que possuam a modalidade inclusiva têm como obrigação reconhecer as diferentes necessidades de seus alunos e as atender, e serem capazes de adaptar-se aos diferentes estilos e ritmos de aprendizagem, assegurando que todos consigam atingir um nível de aprendizagem de qualidade, através de projetos educativos, programas de ensino diversos e etapas avaliativas adequadas.

Entende-se por educação especial, para efeitos desta Lei, a modalidade de educação escolar, oferecida referencialmente na rede regular de ensino, para educandos com necessidades especiais (BRASIL, 1996).

A educação inclusiva constitui um movimento baseado na Declaração Universal dos Direitos Humanos, a qual defende a igualdade de ensino entre os indivíduos e conjuga diversas mudanças nas diretrizes educacionais (BRASIL, 2004).

As palavras "integração" e "inclusão" apresentam diferenças claras, básicas e importantes. Integração vem do uso comum na década de 70, e tinha como ponto central o problema das crianças excepcionais que, de acordo com suas características deveriam ou não ser incorporadas no ensino básico, ou seja, as crianças deveriam ser entregues ao meio para que fossem capazes de se adaptarem, se assim fosse possível. No entanto, a palavra inclusão corresponde a uma visão presente no contexto atual, que reconhece as mais variadas diferenças e tem como objetivo criar um sistema de ensino que incorpore todos no ensino básico, com condições igualitárias, 
sem preconceitos ou segregações (BRASIL, 2005), notando a grande diferença entre tornar o ambiente educativo adequado para atender tais crianças e integrar estas a um meio restrito e indiferente.

Segundo Rodrigues (2006), a escola Integrativa tinha a característica de classificar os alunos em duas categorias, "normais" e "deficientes", e a escola assim era dividida. Os alunos "normais" cursavam de modo tradicional, o mesmo panorama curricular, atividades e seguimentos. Entretanto, para os "deficientes" eram selecionadas condições especiais ou alternativas de suporte, ainda que os critérios principais do currículo escolar permanecessem inalterados. O aluno deficiente estudava na escola integrativa com algumas condições, ou seja, apenas se o aproveitamento e acompanhamento estivessem de acordo com a conduta escolar. Se esses pré-requisitos não fossem atendidos, os alunos "deficientes” corriam o risco de ser devolvida a escola especial, podendose perceber que os alunos deficientes não faziam parte do corpo da escola integrativa.

“A inclusão, não é, a nosso ver, uma evolução da integração" (RODRIGUES, 2006). O caráter de diferença apenas assumia imagem quando se tratava de deficiência, sendo todos os outros valores pertencentes à própria denominação da palavra "diferença” subestimada, distanciando-se ainda mais da proposta inclusiva de educação.

Quadro 1 - Relação das características Integração x Inclusão

\begin{tabular}{|c|c|}
\hline INTEGRAÇÃo & INCLUSÃo \\
\hline Competição & Cooperação/solidariedade \\
\hline Seleção & Respeito às diferenças \\
\hline Individualidade & Comunidade8 \\
\hline Preconceitos & Valorização das diferenças \\
\hline Visão individualizada & Melhora para todos \\
\hline Modelo técnico-racional & Pesquisa reflexiva \\
\hline
\end{tabular}

Fonte: (BRASIL, 2005).

De acordo com a análise de documentos sobre inclusão por Wilson (2000), provenientes do Center for Studies on Inclusive Education, o entendimento do termo Escola Inclusiva nos refere a uma escola centrada na comunidade, isenta de barreiras sejam estas arquitetônicas ou curriculares, que fornece apoio, igualdade e colaboração.

O termo Educação Inclusiva tornou-se foco em campo polêmico, utilizado de forma tão intensa, o qual foi integrado ao discurso de variadas áreas, desde a política, saúde, lazer até ao sistema bancário (RODRIGUES, 2006).

Muitas vezes, a inclusão educativa é tratada como uma utopia, a “ideologia da Inclusão”, não há necessidade de distanciar algo que vem se concretizando aos poucos, mesmo que a passos curtos, em nível de programas políticos e promessas organizacionais de escolas. A Educação Inclusiva é a tão discutida "Educação para Todos”, e uma possibilidade concreta, passível de ser adotada em qualquer escola regular (CORREIA, 2003).

O grande desafio que se faz presente diante o sucesso da escola inclusiva consiste no que diz respeito a ser realmente capaz de educar todas as crianças de maneira eficaz, todas em um nível de qualidade, conseguindo englobar mesmo aquelas que possuam desvantagens severas em comparação as outras (BRASIL, 2005).

Inclusive, deve-se perceber a importância dos investimentos nas adaptações físicas, nas condições de estudo nas salas de aula, na produção e incentivo dos recursos didáticos, projetos de atualização dos profissionais e apoio aos professores, acompanhamento de profissionais adequados e específicos nas escolas (terapeutas, psicólogos, trabalhadores sociais), os quais possam fornecer um embasamento além dos conhecimentos educativos. Além da bagagem ideológica da Educação Inclusiva, não se deve esquecer a crucial importância de tais 
investimentos, pois vivemos em um país com sérias “deficiências” financeiras, e neste caso a palavra se emprega corretamente, no qual o dinheiro aplicado muitas vezes não é bem administrado (RODRIGUES, 2006)

No entanto, o verdadeiro mérito não está no fato destas escolas serem capazes ou não, de fornecerem uma educação de boa qualidade a todos os alunos, e sim no real estabelecimento de tais escolas. Este é um passo crucial no sentido de modificar e eliminar atitudes e pensamentos discriminatórios, os quais classificam as crianças como objetos em "bom ou mau funcionamento", e para finalmente criar um ambiente acolhedor e de agradável convivência, no qual a arte de ensinar-aprender seja prazerosa para ambos os lados na sala de aula (RODRIGUES, 2006)

De acordo com a Lei de Diretrizes e Bases Nacionais (LDB), Lei no. 9.394, de 20.12.1996, capítulo V da Educação Especial:

\begin{abstract}
Os sistemas de ensino assegurarão aos educandos com necessidades especiais:
I - currículos, métodos, técnicas, recursos educativos e organização específicos, para atender às suas necessidades;

II - terminalidade específica para aqueles que não puderem atingir o nível exigido para a conclusão do ensino fundamental, em virtude de suas deficiências, e aceleração para concluir em menor tempo o programa escolar para os superdotados;
\end{abstract}

III - professores com especialização adequada em nível médio ou superior, para atendimento especializado, bem como professores do ensino regular capacitados para a integração desses educandos nas classes comuns;

IV - educação especial para o trabalho, visando a sua efetiva integração na vida em sociedade, inclusive condições adequadas para os que não revelarem capacidade de inserção no trabalho competitivo, mediante articulação com os órgãos oficiais afins, bem como para aqueles que apresentam uma habilidade superior nas áreas artística, intelectual ou psicomotora;

V - acesso igualitário aos benefícios dos programas sociais suplementares disponíveis para o respectivo nível do ensino regular (BRASIL, Art. 59, 1996)

Observando o que é dito no inciso I, currículos, métodos, técnicas, recursos educativos e organização específicos, para atender às suas necessidades, deve-se refletir sobre quais são os responsáveis por produzir ou possibilitar tais recursos, técnicas e métodos, visto que o peso recai sobre os ombros daqueles presentes no, contexto escolar.

Entretanto, o que segue descrito na LDB não condiz com a realidade das escolas públicas de ensino, sabendo-se que os profissionais dentro das salas de aula não estão qualificados para enfrentarem a grande variedade de alunos, com suas respectivas diferenças e desníveis. Inclusive os recém formados em licenciatura sequer possuem um número significativo de disciplinas obrigatórias que se tratem de educação especial, não sendo preparados adequadamente pelas universidades para oferecerem suporte a tais alunos.

A mesma Lei de Diretrizes e Bases Nacionais, citada anteriormente, transfere para os municípios o encargo de universalizar o ensino para os indivíduos na faixa etária de 0 a 14 anos, em outras palavras, envolver todas as crianças e jovens pertencentes à Educação Infantil e Fundamental (BRASIL, 2004).

Logo, o município passa a ter a responsabilidade de formalizar a decisão política e promover ajustes adequados para implementar a educação inclusiva, no âmbito da Educação Infantil e Fundamental (BRASIL, 2004).

No entanto, o amparo das leis e declarações que suportam o processo de inclusão, por si só não é eficaz. Apesar da existência de muitos documentos de importância que afirmam e oferecem embasamento à Educação Inclusiva, tais como a Conferência de Educação para Todos, no dia-a-dia nas escolas, essa situação não é observada ou garantida. O que se percebe é que temos uma grande distância entre o que é proposto e as práticas 
realizadas (SOARES; PAULINO, 2009). A falta de qualificação dos professores presentes no ensino regular ao receber tais alunos nas escolas consiste em um dos maiores obstáculos a serem enfrentados.

Por isto este artigo tem como objetivo analisar a literatura sobre: a educação dos cegos, sua história através das principais legislações, abordando as conquistas das adaptações criadas pelos professores para o ensino de Ciências para esta clientela.

\section{METODOLOGIA}

Para atingir o objetivo geral deste artigo analisamos a literatura, onde foram pesquisadas as obras primárias com a perspectiva de: levantamento de livros e trabalhos especializados nas bibliotecas e pelos sites especializados como Pubmed, Scielo e Google Acadêmico. Este levantamento inicial foi feito com o cruzamento de uma série de palavras-chave previamente estabelecidas. As palavras-chave utilizadas foram: legislações, declarações, portarias, cegueira, ensino e educação de cegos, ensino de ciências para os cegos.

\section{RESULTADOS}

\section{1 Educação inclusiva: Marcos Históricos e Legislação}

Ao longo do tempo, a educação dos indivíduos com deficiência foi caracterizada basicamente em quatro fases: i) a fase da negligência, durante a época pré-cristã, na qual era quase nulo o atendimento aos indivíduos, sendo estes por muitas vezes excluídos do convívio com a sociedade; ii) a fase da institucionalização, com a reclusão e atendimento em casas de abrigo (o que aconteceu também com os hansenianos); iii) a fase da criação das escolas especiais que forneciam aos deficientes uma educação exclusiva, com atendimento assistencialista médico-pedagógico e psicopedagógico, substitutivo ao ensino regular; e por último, iv) a fase do movimento de integração social, o qual tentava incorporar os alunos “excepcionais” em ambientes escolares, mas somente até onde se achava que a capacidade dos mesmos podia alcançar. (MIRANDA, 2008)

Um dos primeiros momentos significativos da história da Educação Especial corresponde ao final do século XVIII e início do século XIX, conhecido pela Era das Instituições ou fase de segregação institucional, como dito anteriormente. É nesse período que de fato a Educação Especial segue seus primeiros passos, quando se percebe a necessidade das pessoas com deficiência e determinadas medidas de assistência são tomadas, tais como a criação dos conselhos estaduais de educação e a cooperação financeira assegurada por lei às escolas privadas. No entanto, os deficientes continuavam sendo discriminados e postos à margem da sociedade e da família, atendidos por instituições voluntárias, com a permissão do governo, porém sem nenhum outro tipo de apoio (CAMARGO, 2004).

Apesar de muitas barreiras, houve o surgimento importante de instituições, tais como "Instituto dos Meninos Cegos" criado em 1854, atualmente conhecido como Instituto Benjamin Constant (IBC), o "Instituto dos Surdos-Mudos” criado em 1857, hoje Instituto Nacional de Educação de Surdos (INES), ambos fundados pelo governo Imperial, na cidade do Rio de Janeiro. (JANNUZZI, 1992; MAZZOTTA, 1996; BUENO, 1999). Além da Sociedade Pestalozzi, na década de 1930, Associações de Pais e Amigos dos Excepcionais (APAE), na década de 1950, e unidades de reabilitação no início dos anos 1960. (SOARES, PAULINO, 2009).

A criação do IBC e do INES representou uma grande conquista em relação ao atendimento dos deficientes, não só na cidade do Rio de Janeiro como também em nível mundial. Isso permitiu não só a abertura de um espaço para a conscientização das pessoas, mas também a própria discussão sobre como a educação estava sendo feita e qual parcela era atendida. Contudo, logo de início, isto "se constituiu em uma medida precária em termos 
nacionais, pois em 1872, com uma população de 15.848 cegos e 11.595 surdos, no país eram atendidos apenas 35 cegos e 17 surdos” nestas instituições (MAZZOTTA, 1996, p. 29).

Segundo Mendes (1995), foi a partir dos anos 50, mais precisamente no ano de 1957, o atendimento educacional aos indivíduos com deficiência foi adotado pelo governo federal, com a criação de campanhas, como a "Campanha para a Educação do Surdo Brasileiro". Logo em seguida, em 1958, também surgiu a "Campanha Nacional de Educação e Reabilitação do Deficiente da Visão", e em 1960 a "Campanha Nacional de Educação e Reabilitação de Deficientes Mentais" - CADEME. O objetivo da CADEME era desenvolver em território Nacional, a "educação, treinamento, reabilitação e assistência educacional das crianças retardadas e outros deficientes mentais de qualquer idade ou sexo”. (MAZZOTTA, 1996, p. 52).

Em 1970 foi criado o Centro Nacional de Educação Especial - CENESP, no MEC, com o intuito de gerenciar a educação especial no Brasil, regido por um foco integracionista, o que impulsionou ações educacionais voltadas às pessoas com deficiência e aos superdotados. No final da década, foram implantados os primeiros cursos de formação de professores na área da Educação Especial e em 1985. O Ministério da Educação, conhecido antigamente por "Ministério da Educação e Saúde Pública” foi criado em novembro de 1930, e era responsável por tratar de assuntos relacionados, como próprio nome dizia, à área da educação e saúde. (BRASIL, 2007)

As ações voltadas ao atendimento educacional destas pessoas fundamentavam-se nas disposições da Lei de Diretrizes e Bases da Educação Nacional n 54.024/61, a qual direcionava o direito dos “excepcionais” à educação.

Em uma linha do tempo, as propostas na legislação brasileira sofreram rearranjos seguindo os conceitos variados que a escola inclusiva assumia, incorporando mais o estilo da união da educação com a escola comum, separado da assistência social com a instituição especializada, para o número diverso de alunos em questão. Uma das grandes responsabilidades herdadas pelos sistemas estaduais e municipais de ensino é dever de assumir uma parcela significativa do alunado com necessidades educacionais especiais, os quais necessitam do apoio de instituições, e além daqueles que não possuem ainda acesso a qualquer serviço educacional. (FERREIRA, 1998)

Em 1988, a Constituição da República Federativa do Brasil teve formalmente, declarada os mesmos princípios esclarecidos na Declaração Universal dos Direitos Humanos. Além disso, a descentralização do poder foi uma característica de uma nova atitude administrativa introduzida no país (BRASIL, 2004).

Aliás, deve-se destacar na Constituição Federal, o inciso III do Artigo 208, o qual define como dever do Estado o "atendimento educacional especializado aos portadores de deficiência, preferencialmente na rede regular de ensino". As Constituições estaduais, em grande medida, apenas repetem a Constituição Federal. A partir desta, somente são acrescentados tópicos específicos relacionados à educação, a exemplo da implantação de Braille em classes da rede oficial e de níveis ou modalidades de ensino (FERREIRA, 1998).

No cenário internacional, temos como eventos importantes no âmbito da Educação Inclusiva: Conferência Mundial sobre Educação para Todos (Tailândia, 1990), e em especial, a Declaração de Salamanca (1994), a qual fortalece as referências às necessidades educativas especiais, confronta leituras e reconfigura noções do próprio aluno e suas necessidades (FERREIRA, 1998), e logo após, a Convenção da Guatemala (1999).

A Declaração de Salamanca foi estabelecida na conferência Mundial em Educação Especial realizada entre 7 e 10 de junho de 1994. A conferência foi organizada pelo governo da Espanha em cooperação com a UNESCO com o objetivo de divulgar e fornecer informações à respeito de políticas e guias de ações governamentais, de organizações internacionais ou agências nacionais de auxílio, organizações não-governamentais e outros, sobre princípios Política e prática em Educação Especial (BRASIL, 1994). 
A declaração está fundamentada sobre os alicerces da Declaração Universal dos Direitos Humanos (1948), os quais defendem e reafirmam os direitos de qualquer pessoa portadora de deficiência em expressar seus desejos à respeito da sua educação, tanto quanto estes possam ser atendidos e realizados. Esta ainda inclui a questão, quanto aos responsáveis possuírem o direito inerente de serem consultados sobre a forma de educação mais apropriada às necessidades, circunstâncias e aspirações de suas crianças. Essa declaração fortaleceu ainda mais a questão de que, todas as escolas devem atender as crianças, sem restrições, além de suas características físicas, intelectuais, sócio-econômicas, emocionais, entre outras, com a capacidade de fornecer uma pedagogia qualificada e equilibrada, capaz de beneficiar todas as crianças de forma justa e igualitária (BRASIL, 2004).

Como grandes desafios, de acordo com a Declaração de Salamanca foram propostas diversas mudanças no cenário educativo não somente restrito a escola, mas em todos os ambientes relacionados que possam influenciar e atuarem por entremeios facilitadores, tais como: fatores relativos à escola; recrutamento e treinamento de educadores; serviços externos de apoio; áreas prioritárias; perspectivas comunitárias; requerimentos relativos a recursos, e entre muitos outros (BRASIL, 1994).

\section{2 A Educação Especial e a Deficiência Visual}

O Censo Escolar registra alguns dados na educação especial, quanto a evolução nas matrículas, de 337.326 em 1998 para 702.603 em 2010, constituindo um crescimento de 107\% até 2006. A partir daí, constata-se um decréscimo no número total de matrículas, voltando a crescer em 2010 para 702.603.

Ao que se refere ao ingresso em classes comuns do ensino regular, nota-se um crescimento de $640 \%$, até 2006, passando de 43.923 alunos em 1998 para 325.316 em 2006 como mostra na Figura 1.

\section{Figura 1 - Gráfico mostra o crescimento do número de matrículas em escolas especiais/ classes especiais/modalidade especial e escolas regulares/classes comuns/alunos incluídos}

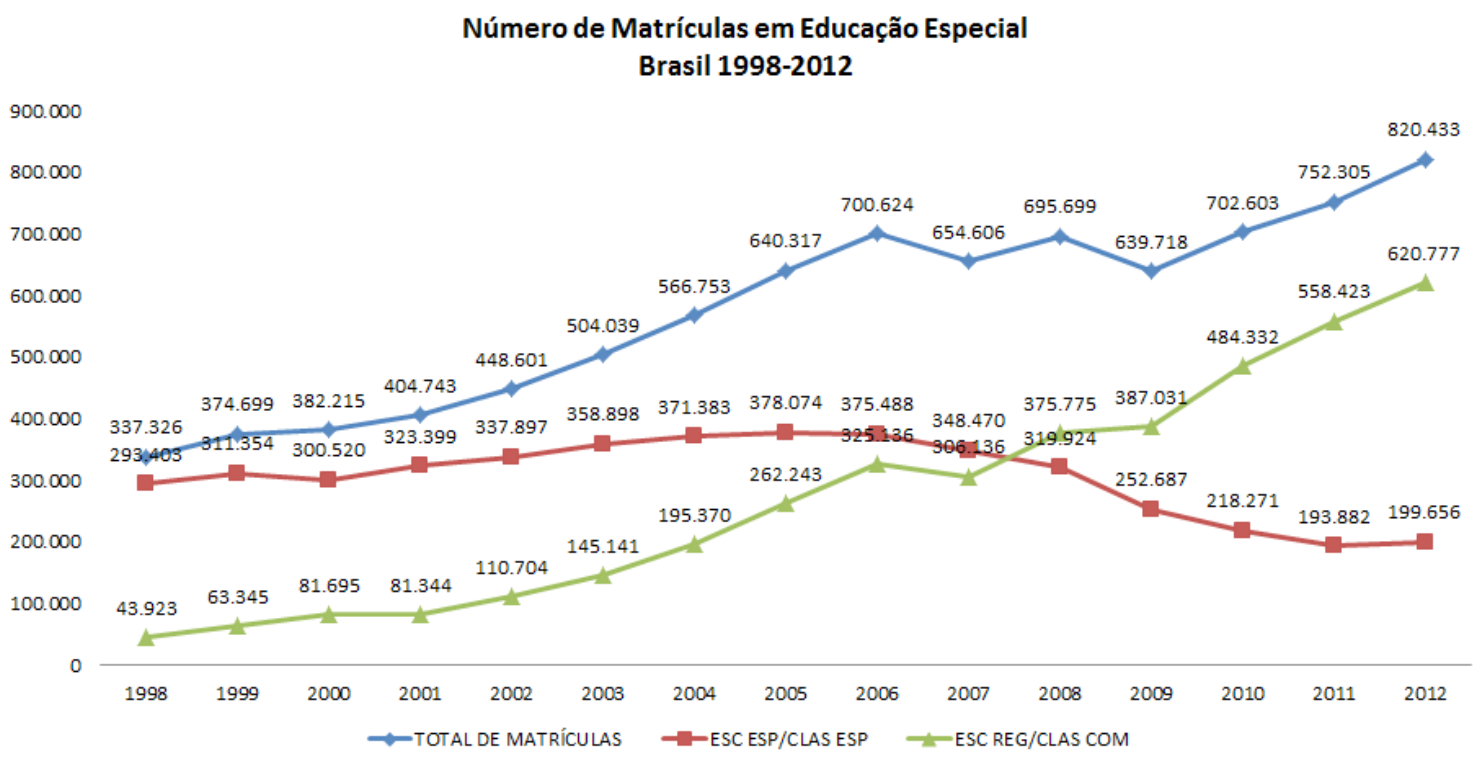

Fonte: Censo Escolar MEC/INEP, 2007; Censo da Educação Básica, 2012.

O interesse pela educação dos indivíduos cegos iniciou-se no século XVIII, quando o educador francês Valentin Haüy (1745-1822), o qual era considerado o "Pai da educação dos cegos", criou um método oficial de leitura para cegos em 1784, (CAMARGO, 2004). 
Atualmente o Instituto Benjamin Constant está dentre as instituições responsáveis por cuidar dos assuntos relacionados a cegueira, se tratando de um Centro de referência, a nível nacional, a respeito dos assuntos relacionados à deficiência visual. Dentre suas muitas ações, segue a escola bem estruturada, capacitação de profissionais da área da deficiência visual, assessoria de escolas e instituições, consultas oftalmológicas à população, reabilitação, produção de materiais especializados, impressões em Braille, publicações científicas e livros didáticos (BRASIL, 2005).

Segundo a definição da Secretaria de Educação Especial, a cegueira corresponde a "perda ou redução total da capacidade de ver com o melhor olho e após a melhor correção óptica” (BRASIL, 1994 p. 16), ou seja, constitui a incapacidade total ou a diminuição da capacidade de enxergar, oriundas das imperfeições do sistema visual ou do próprio órgão. O indivíduo que possua baixa visão tem uma perda visual severa, no entanto, é capaz de manter um resíduo visual que é único de cada pessoa e não depende apenas da acuidade ou da patologia. Em um leque de possibilidades, esse resíduo pode diversificar entre as pessoas, e seu uso pode estar relacionado somente com algumas atividades do cotidiano, inclusive a utilização da leitura e escrita em tinta, com recursos especializados (ópticos, não-ópticos e eletrônicos). (BRASIL, 2005)

De acordo com Barraga (1976), podem se distinguir três tipos de deficiência visual: i) os cegos, que tem apenas a percepção da luz ou sem visão alguma e necessitam utilizar com outros meios de comunicação, assim como o Braille e outros que não estejam relacionados com o sentido da visão; ii) indivíduos com visão parcial que possuem limitações quanto a visão distante, porém conseguem ver objetos e materiais quando próximos aos olhos ou no máximo a meio metro de distância; iii) os indivíduos com visão reduzida, que são aqueles que podem ter seu problema corrigido por cirurgias ou pela utilização de lentes.

Para que a criança cega consiga compreender as informações que lhe são fornecidas de forma precisa, é preciso desenvolver determinadas habilidades já nas séries iniciais. Caso não exista um direcionamento adequado logo nos primeiros anos de vida à criança deficiente visual, pode-se desenvolver um atraso nos desenvolvimentos cognitivo, físico e psicossocial. O tato é um dos sentidos que deve ser treinado continuamente durante um processo de diferenciação de diversos materiais e das características dos mesmos, tais como a textura, relevo, forma e peso (CROZARA \& SAMPAIO, 2008).

Existem pesquisas atuais que demonstram a capacidade de indivíduos cegos reconhecerem desenhos bidimensionais. Kennedy e seus colaboradores mostraram que tais indivíduos conseguem compreender desenhos em alto relevo e alcançam um entendimento básico do espaço em seus desenhos (KENNEDY, 1983; KENNEDY, DOMANDER, 1984; KENNEDY, FOX, 1977; KENNEDY, GABIAS, 1985; HELLER, 1989 apud LIMA \& da SILVA, 2005).

Caso seja fornecido um tempo necessário aos cegos congênitos, os mesmo são capazes de reproduzir tais informações, em seus desenhos, bem como, interpretá-las nas figuras. Aliás, muitos estudos tem enfatizado, os benefícios que a interação com padrões em 2D podem possibilitar aos jovens cegos, como exemplo, fornecendolhes informações espaciais vantajosas (HELLER, 1989, 1991; HELLER, JOYNER, 1993; HELLER, KENNEDY, 1990; HELLER, KENNEDY, JOYNER, 1995; KENNEDY, 1993; MILLAR, 1975, 1991, apud LIMA, da SILVA, 2005).

O Censo 2010 divulgado pelo Instituto Brasileiro de Geografia e Estatística (IBGE), mostrou que a deficiência visual aumentou no Brasil (18,8\%), (Figura 2). Entre as regiões brasileiras, como exposto na Figura 2 o Nordeste foi a que apresentou maior crescimento da população com pelo menos um tipo de deficiência (21,2\%). A análise dos diferentes tipos de deficiência investigados mostrou que a deficiência visual foi a que mais se destacou em todas as regiões. O Nordeste também foi a região que apresentou maior número de deficiências severas (4,1\%). 

Figura 2: População com deficiência segundo o tipo de deficiência (A), com pelo menos um tipo
de deficiência (B), por tipo de deficiência investigada (D), por tipo de deficiência severa.
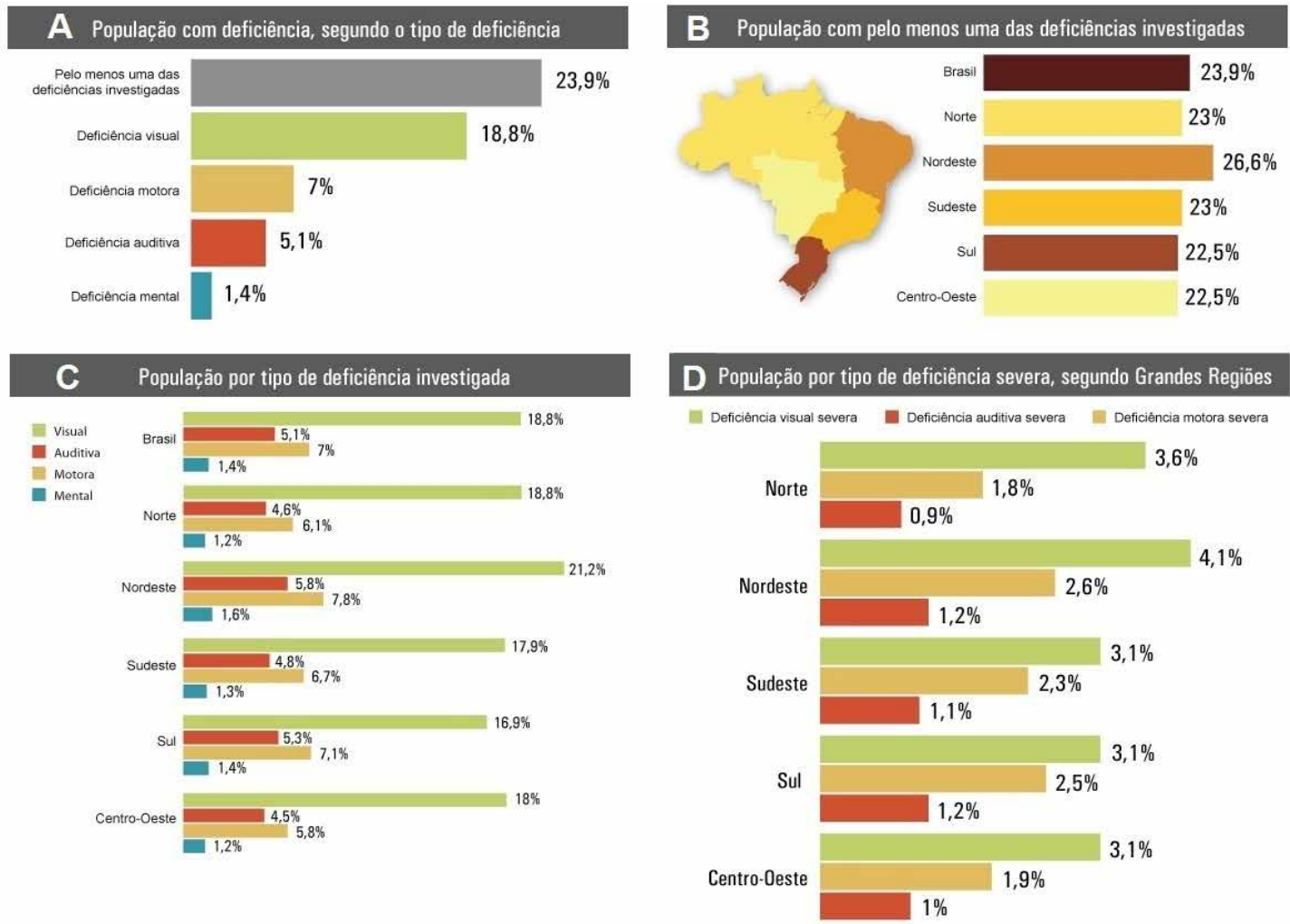

Fonte: IBGE - Censo 2010.

\section{3 Deficiência Visual e Cegueira e Recursos Didáticos}

Os recursos pedagógicos inclusivos, no contexto educacional, podem incrementar a adequação das propostas didáticas, de modo que considerem as necessidades do alunado e que forneça novas alternativas de organização do saber. A recém descoberta Tecnologia Assistiva tem como objetivo desenvolver recursos de acessibilidade, o que corresponde a uma alternativa concreta de eliminar os empecilhos causados pela deficiência e incluir tal indivíduo em ambientes ricos para a aprendizagem, proporcionados pela cultura. (BERSCH, 2008)

"Para as pessoas sem deficiência, a tecnologia torna as coisas mais fáceis. Para as pessoas com deficiência, a tecnologia torna as coisas possíveis.” (RADABAUGH, 1993).

A utilização de materiais didáticos é de suma importância, quando se trata da educação de deficientes visuais, visto os diversos problemas enfrentados pelos mesmos durante o processo de assimilação de conhecimentos. Como exemplo podemos citar a dificuldade de contato com o ambiente físico, escassez de materiais didáticos apropriados e a carência de etapas educativas estimulantes similares as existentes para as crianças com visão normal. (CERQUEIRA \& FERREIRA, 2000)

Em especial, o aluno que possui deficiência visual necessita de um ensino com variadas adaptações que sejam suficientes para atender suas necessidades no ambiente escolar. O educador tem como dever, realizar uma busca por informações relacionadas com os sentidos remanescentes, tais como a audição, olfato, tato e paladar, com o intuito de ampliar o horizonte de oportunidades de aprendizado. (SCHNEIDER, 2009) 
Vale ressaltar que o número de palavras que um cego experiente consegue ler por minuto é menos de metade da média dos leitores videntes experientes (OCHAITA, ROSA, 1995). Além disso, várias pesquisas detectam que a leitura tátil é três vezes mais cansativa que a leitura visual (GIL, 2000). Assim, considerar que aulas baseadas em livros didáticos traduzidos para o Braille, sem inclusão de figuras táteis, são suficientes para esses alunos, principalmente na área de Ciências da Natureza e suas Tecnologias é um equívoco que prejudica exclusivamente o aluno com necessidade especial visual.

Segundo Cerqueira \& Ferreira (2000), os recursos didáticos podem ser classificados como: pedagógicos (jogos, maquetes, cartazes), naturais (água, vento, pedra), tecnológicos (rádio, TV, vídeo, computador) e culturais (biblioteca, museu, exposições e outros). Consistem em áreas de pesquisa ou estudos, recursos físicos, técnicas, metodologias e atividades empregadas que tenham como foco auxiliar e beneficiar a aprendizagem do educando.

Os recursos podem ser obtidos através de três formas (seleção, adaptação e confecção), e devem para sua melhor eficiência serem fartos, variados e significativos, de modo que possam atender maior número de indivíduos, além de serem estimulantes e com informações relevantes diversas (CERQUEIRA \& FERREIRA, 2000). Além disso, a atualização dos recursos referentes as diferentes áreas do conhecimento é algo premente sempre posto que estas não são estáticas. Na área das Ciências da Natureza e Matemática e suas tecnologias, isso perpassa por uma necessidade intrínseca do conhecimento gerado e alimentado pela pesquisa e que se traduz na edições de livros didáticos cada vez mais ilustrados e ricos em textos analógicos visuais.

A produção dos recursos pedagógicos inclusivos pode ser realizada pelo próprio educador com poucos materiais disponíveis e inclusive, de baixo custo, contudo o educador deve ter como base determinados critérios significativos para a eficiência de sua utilização. (SCHNEIDER, 2009) De acordo com a Revista Nossos Meios RBC, artigo 3 (CERQUEIRA \& FERREIRA, 2000) existem alguns direcionamentos simples, porém significativos que auxiliam muito na confecção ou produção de materiais inclusivos os quais podem fazer parte do ambiente escolar nas salas de recursos.

Dentre estes direcionamentos, podemos citar:

- A representação deve ser fiel ao modelo original;

- Atraente para os alunos de baixa visão e agradável ao tato;

- Apropriado para o conteúdo, a necessidade e a faixa etária;

- Dimensões e tamanhos adequados, que não seja muito pequeno e perca o valor dos detalhes e não muito grande para não prejudicar a compreensão do todo;

- Cores fortes e contrastantes que possam melhor se adaptar as limitações visuais do aluno;

- O relevo deve ser simplesmente perceptível ao tato;

- Que possua diferentes texturas, como liso/áspero, espesso/fino;

- Simples e de manuseio fácil e que não ofereça perigo ao aluno.

Como exemplo de recursos didáticos específicos para os deficientes visuais, temos presentes nas salas de recursos das escolas, os modelos, mapas geográficos, políticos, históricos, livros falado, auxílio de vídeos e TV, além do grande auxílio da impressora Braille, Thermoform, DOSVOX, scanners, e outras tecnologias disponíveis no mercado, no entanto com pouca disponibilidade para os demais. (CERQUEIRA \& FERREIRA, 2000)

O mapa é um ótimo recurso para ajudar um aluno cego na organização de suas imagens espaciais internas. Segundo Fonseca (1999), existe quatro tipos básicos de mapas para cegos que podem ser destacados: mapas de papel, gravados em relevo; mapas seccionais, em relevo ou planimétricos, de madeira ou borracha; mapas moldados de papel ou plástico; e mapas especiais, não reproduzíveis, feitos à mão. Além disso, é importante a combinação de textos em Braille e alto-relevo, e inclusive, a identificação das trilhas táteis no espaço mapeado, com variadas cores e texturas que servem como critério para a representação das mesmas. (SGARABOTTO \& DURANTI, 2007) 


\section{Quadro 2 - Principais critérios relacionados à construção dos recursos didáticos da Educação Especial dos alunos deficientes visuais}

\begin{tabular}{|c|c|c|}
\hline CRITÉRIOS & CARACTERÍSTICAS DOS RECURSOS & EXEMPLOS \\
\hline SELEÇÃO & $\begin{array}{c}\text { Utilizados pelos alunos videntes e podem ser } \\
\text { aproveitados pelos alunos deficientes visuais. }\end{array}$ & Sólidos geométricos, jogos. \\
\hline ADAPTAÇÃO & $\begin{array}{c}\text { Com algumas alterações, podem servir } \\
\text { para alunos cegos e de baixa visão. }\end{array}$ & $\begin{array}{c}\text { Instrumentos de medir, } \\
\text { mapas de encaixe. }\end{array}$ \\
\hline CONFECÇÃO & $\begin{array}{c}\text { Elaboração de materiais de baixo custo, como palitos } \\
\text { de fósforos, contas, barbantes, cartolinas, botões. }\end{array}$ & $\begin{array}{c}\text { Reações e Moléculas Químicas } \\
\text { Mapas hidrográficos, } \\
\text { mapas políticos. }\end{array}$ \\
\hline RESISTÊNCIA & $\begin{array}{c}\text { Devem ser confeccionados com materiais que } \\
\text { não se estraguem com facilidade, considerando } \\
\text { o freqüente manuseio pelos alunos cegos. }\end{array}$ & $\begin{array}{c}\text { Objetos feitos de borracha, } \\
\text { lona, plástico. }\end{array}$ \\
\hline FIDELIDADE & $\begin{array}{c}\text { O material deve ter a sua representação tão exata } \\
\text { quanto possível do modelo original. Usados tanto } \\
\text { para alunos videntes como para alunos deficientes. }\end{array}$ & $\begin{array}{c}\text { Modelos de acidentes geográficos } \\
\text { para representar uma montanha. }\end{array}$ \\
\hline TIGNIFICAÇÃOTÁTIL & $\begin{array}{c}\text { Devem ser confeccionados ou selecionados em tamanho } \\
\text { adequado às condições dos alunos cegos e de baixa-visão. } \\
\text { Materiais muito pequenos não ressaltam os detalhes de } \\
\text { suas partes componentes ou perdem-se com facilidade. }\end{array}$ & $\begin{array}{c}\text { Objetos situados a grandes } \\
\text { distâncias (formatos de } \\
\text { uma nuvem, sol, lua). }\end{array}$ \\
\hline
\end{tabular}

Fonte: (CERQUEIRA, BECHARA, 1996).

De acordo com a orientação SD nº 01/2005, esses recursos didáticos devem estar presentes na sala de recursos, que é caracterizada como um atendimento educacional especializado, que tem como objetivo complementar a ação do atendimento educacional comum, em contra turno ao horário escolar, sendo direcionada para os alunos que apresentam algum tipo de deficiência, sejam estas as mais diversas ou condutas típicas, tais como síndromes e quadros psicológicos complexos, neurológicos ou psiquiátricos persistentes, sendo matriculados em escolas regulares comuns em qualquer seguimento. (BRASIL, 2009).

A sala de recursos é um espaço disponibilizado para o atendimento dos variados alunos com necessidades educacionais especiais, podendo ser composta por diferentes equipamentos e materiais pedagógicos, e organizada de acordo com quadro de horários disponíveis, em uma espécie de rodízio, com alunos cegos, com baixa visão, surdos, com deficiência física, mental ou deficiência múltipla, desde que o professor seja habilitado para tal função. A proposta pedagógica definida deve ser organizada seguindo as específicas condutas ou deficiências do aluno, com etapas, atividades e programas educacionais exclusivos. (BRASIL, 2009).

As atividades desenvolvidas neste atendimento têm como foco suplementar os conteúdos escolares, como exemplos Biologia, Matemática, Português e/ou os demais. A Sala de Recursos não é um espaço utilizado para aulas de reforço, ou de assistência clínica ou social. Existe uma característica fundamental nesse tipo de trabalho, que é o caráter pedagógico, o qual assume como papel principal atender as necessidades do alunado, assegurando a acessibilidade aos recursos existentes, que lhe são de direito e que possam aprimorar suas habilidades, isso deverá desenvolver o processo de aprendizagem do aluno e, posteriormente, permitindo que este o aluno alcance sua própria independência, possibilitando, então, um convívio social equilibrado. (BRASIL, 2009). 
A complexidade nos temas da área da Biologia consiste em um desafio para qualquer alunado, independente das características destes. Contudo, especialmente para aqueles com deficiência visual, a abordagem é ainda mais difícil. Tópicos como o Reino Monera exigem novas abordagens que viabilizem a compreensão dos respectivos conteúdos inerentes ao mesmo. A morfologia das bactérias é um exemplo de tópicos que pode se utilizar de diferentes técnicas para criação de novos materiais didáticos podendo ser representadas em papel vegetal, gravadas em alto relevo com diferentes texturas, ou seja, constituindo uma mescla de tipos de caracterização de imagens, contribuindo para a organização de idéias do aluno cego ou com necessidades visuais especiais.

Observamos na literatura a extrema importância que os alunos tenham uma variedade de propostas que forneçam apoio para realizar as atividades escolares, tais como confecção cartazes, materiais táteis, pinturas, que permitam que eles toquem nas telas, explorando os sentidos tátil, visual e sinestésico, que provocam sensações múltiplas, além de obter informações acompanhadas, através do Braille e da legenda em letras ampliadas (FIGUEIRA, 2003). É importante para eles receberem materiais que possam beneficiar seus estudos além de motivá-los, e especial saber que existem profissionais que estão buscando se aprimorar e se interessam em melhorar suas condições de estudo.

Recursos gráficos de apoio ao texto escrito; programas de ensino com o auxílio do computador; pesquisas em livros, revistas, jornais, internet; leituras de textos literários e poesias; apresentação de seminários e entre vários outros ainda tem que ser produzidos para que o aluno com deficiência possa escolher a forma que mais lhe agradar de aprender (BRASIL, 2006).

Trabalhos como de Lima \& Da Silva (2005) que desenvolveram uma caneta para desenho em alto-relevo, permitindo a produção de atividades criativas por pessoas cegas ou deficientes visuais, abrem um novo espaço para que inclusive outras atividades profissionais possam ser desenvolvidas.

De acordo com Zabala (1998) o material didático deve ser selecionado de acordo com o seu foco no processo de aprendizagem seja para informar, reforçar, memorizar, contextualizar, compreender ou descontextualizar. Depois que a função é definida, fica mais fácil selecionar o material adequado para a tarefa a ser desenvolvida.

Segundo Ormelezzi (2000) pode-se constatar que a formação de imagens e conceitos de participantes cegos, dá-se através de experiências sensoriais, tátil, auditiva ou olfativa, inter-relacionadas com a linguagem das pessoas envolvidas. E, em se tratando de conceitos pouco ou nada distinguíveis à percepção, pode-se verificar significados consistentes relacionados a linguagem.

Os indivíduos cegos ou com deficiência visual possuem uma forma diferente de aprendizagem, isso implica dizer que para construir seus conceitos, o aluno necessita de um tempo maior para experimentar, aprender e em sequência, organizar suas vivências (MEDEIROS et. al., 2007; FERREIRA, DICKMAN, 2007; 2008 apud AMARAL et al., 2008). Inclusive, percebe-se que alunos cegos possuem condições em mesmo nível que os videntes de aprender e construir seu próprio universo de conceitos, entretanto, os critérios diferenciais são as metodologias e recursos utilizados para desenvolver tais processos. (RIBEIRO, 2001)

A escassez de trabalhos a respeito da produção de materiais didáticos na área da Biologia e/ou Ciências foi observado, sendo que a disciplina com maior quantidade de recursos paradidáticos é aparentemente a Geografia, o que se pode notar através da quantidade de trabalhos citados e consultados (CROZARA \& SAMPAIO, 2008; BRASIL, 2006; SGARABOTTO \& DURANTI, 2006).

\section{4 Recursos inclusivos e Biologia: como ensinar o quase abstrato como algo real?}

A Educação Inclusiva está evoluindo, mas ainda há muito que crescer e se desenvolver na mentalidade dos profissionais da educação, de modo que "estudar" e "aprender" sejam adequados, acessíveis e de qualidade para todos. Conteúdos que possuam bases metodológicas, que incorpore em suas ações pedagógicas a experiên- 
cia de como é ter alunos diversos com necessidades especiais diferentes no espaço escolar, estimulando-os a produzir matérias acessíveis para o atendimento destes alunos especiais, ainda está ausente nos diversos currículos universitários dos educadores em formação, sendo necessárias ainda disciplinas e programas que possam atuar de forma positiva na proposição de novos materiais (AMARAL et al., 2008).

O uso de modelos bi e tridimensionais ajuda a melhorar a capacidade de adquirir, memorizar e assimilar as informações. A aplicação desses em sala de aula pode ser um importante apoio para o processo de ensino-aprendizagem (ORLANDO et al., 2009).

A partir deste contexto, não deve haver limites nos educadores para a criatividade e para a utilização de recursos pedagógicos e estratégias adequadas que motivem a vontade de aprender. (OLIVEIRA, 2003). Porém, esses materiais têm que ser utilizados de forma a estimular a exploração e o desenvolvimento de outros sentidos, o acesso ao conhecimento, à comunicação, sendo a aprendizagem dependente da qualidade, variedade e adequação destes materiais (SÁ et al, 2007).

Segundo Figueira (2003) é preciso que a escola ofereça uma variedade de propostas que forneçam apoio para que esses alunos possam realizar as atividades escolares isso inclui a questões das áreas de conhecimento que demandam uma variedade de propostas devido a variedade de conceitos. A literatura relata que alunos com necessidades educacionais especiais visuais aprendem de forma diferente, Os indivíduos cegos ou com baixa visão possuem uma forma diferente de aprendizagem para construir seus conceitos, pois necessitam de um tempo maior para experimentar, aprender e em sequência, organizar suas vivências demandando essas alternativas de aprendizagem (DICKMAN \& FERREIRA, 2008; Ribeiro 2001),

Considerando a Biologia e seus conceitos, os modelos parecem atuar como ferramentas de aprendizagem, na medida em que estimulam o interesse do aluno e ajudam no processo de socialização e na construção de novas descobertas. Eles podem ser utilizados como auxiliares no processo de ensino-aprendizagem, possibilitando uma maior aproximação dos alunos com o conteúdo, não só aqueles com necessidades especiais, mas também para os videntes. Para atender todos os alunos, um modelo inclusivo deve possuir texturas e cores diferentes que irão atender as necessidades dos alunos deficientes visuais e ainda atrair a atenção dos alunos videntes com cores fortes e vibrantes (BATISTA, 2005). Portanto, o material deve apresentar cores contrastantes, texturas e tamanhos adequados para que se torne útil e significativo (SÁ et al., 2007). É importante considerar que o material concreto reduz a abstração nas situações de aprendizado, reduzindo também as exposições verbais, o que atende a realidade psicológica do aluno, seja ele com necessidades especiais ou não, independentes da área de conhecimento (ibidem, 1996, s.p.)

Para isso, as escolas devem atender a todos, adaptando a aprendizagem a cada um (TIERNEY, 1993 apud SÁNCHEZ, 2005). Buscando formas de educar que respeitem as singularidades de seu público (SÁNCHEZ, 2005). Os professores precisam estar atentos a diversidade, aceitando as diferenças e propondo atividades que contemplem os seus alunos (SÁ et al, 2007). 


\section{REFERÊNCIAS}

AMARAL, Graziele Kelly; Ferreira, Amauri Carlos; Dickman, Adriana Gomes. Educação de estudantes cegos na escola inclusiva: o ensino de Física. XVIII Simpósio Nacional de Ensino de Física. Vitória (ES), SNEF, 2009 Psicologia: Teoria e Pesquisa, v. 21, n. 1, p. 7-15, 2005.

BERSCH, Rita. Introdução à Tecnologia Assistiva. CEDI - Centro Especializado em Desenvolvimento Infantil. Porto Alegre. 2008. 19 p.

BRASIL. Congresso Nacional. Lei no 9.394, de 20/12/1996. Fixa diretrizes e bases da educação nacional. Diário Oficial da República Federativa do Brasil. Brasília, nº 248, de 23/12/1996.

. Educação Inclusiva: Um meio de Construir Escolas para Todos no Século. XXI Inclusão: Rev. da Educação Especial. Secretaria de Educação Especial. Brasília, 2005.

FIPE/MEC/INEP. Projeto de estudo sobre ações discriminatórias no âmbito escolar, organizadas de acordo com áreas temáticas, a saber, étnico racial, gênero, orientação sexual, geracional, territorial, de necessidades especiais e socioeconômica: sumário dos resultados da pesquisa. Brasília, 2009.

Instituto Nacional de Pesquisas Educacionais Anísio Teixeira. Sinopse estatística da educação básica: censo escolar 2004. Brasília, DF: O Instituto, 2004.

MEC - Ministério da Educação e Cultura. Declaração de Salamanca e linha de ação sobre necessidades educativas especiais. Brasília: CORDE, 1997.

Ministério da Educação. Educação inclusiva: atendimento educacional especializado para a deficiência mental. 2 ed. / Cristina Abranches Mota Batista, Maria Teresa Egler Mantoan. - Brasília: MEC, SEESP, 2006.

Ministério da Educação. Política Nacional de Educação Especial na Perspectiva da Educação Inclusiva. Brasília: SEESP, 2007.

Ministério da Educação. Secretaria de Educação Especial. Documento subsidiário à política de inclusão. Brasília: SEESP, 2007.

Ministério da Educação. Secretaria de Educação Especial. Política Nacional de Educação Especial na Perspectiva da Educação Inclusiva. Brasília: MEC/SEESP, 2008. Disponível em: <http://portal.mec.gov.br/ seesp/arquivos/pdf/politica.pdf $>$. Acessado em: 8 dez. 2013.

Ministério da Educação (MEC) Documento subsidiário à Política de Inclusão. Secretaria de Educação Especial. Brasília, 2005. Disponível em: http://portal.mec.gov.br/seesp/arquivos/pdf/ docsubsidiariopoliticadeinclusao.pdf. Acessado em: $08 \mathrm{dez} 2013$.

Censo 2010. Brasília, IBGE, 2010.

BUENO, J. G. S. Crianças com necessidades educativas especiais, política educacional e a formação de professores: generalistas ou especialistas? Rev. Bras. Edu. Esp. Piracicaba, Ed. UNIMEP , v. 5, 1999.

CAMARGO, E.P.; Ensino de Física para Alunos com Deficiência Visual: Atividade que Aborda a Posição de Encontro de dois Móveis por meio de um Problema Aberto. In: IX Encontro De Pesquisa Em Ensino De Física, 2004, Jabuticatubas-MG, Anais eletrônicos. Jabuticatubas-MG, SBF, 2004( c ). Disponível em: <http:// www.sbf.if.usp.br/ixepef>. Acesso em: 8 dez. 2013. 
CAMARGO, E. P.; SILVA, D. Desmistificar a Deficiência Visual como Primeiro Passo para Ações Educativas de Física. In: Saberes Teóricos e Saberes da Prática na Formação dos Professores: $5^{\circ}$ Congresso Regional De Educação, 2004, São José do Rio Pardo-SP. Anais eletrônicos, São José do Rio Pardo: FEOB, 2004 (a).

CERQUEIRA, J. B. \& FERREIRA, E. de M. B. Recursos Didáticos na Educação. Nossos Meios. RBC. Artigo 3. Rev. Abr. 2000.

Recursos didáticos na educação especial, Revista Benjamin Constant, 2000.

CORREIA, L.; CABRAL, M. Práticas tradicionais da colocação do aluno com necessidades educativas especiais. In: CORREIA, L. (Dir.). Alunos com necessidades educativas especiais nas classes regulares. Porto: Porto, p. 11-16, 1999.

Uma Nova política em educação. In: CORREIA, L. (Dir.). Alunos com necessidades educativas especiais nas classes regulares. Porto: Porto, p. 17-43, 1999a.

CROZARA, T.F., SAMPAIO, A. A. M. Construção de Material Didático Tátil e o Ensino de Geografia na Perspectiva da Inclusão. Universidade Federal de Uberlândia, 2008.

DECLARAÇÃO UNIVERSAL DOS DIREITOS HUMANOS, 2004. Disponível em: <http: //www.onubrasil.org.br/documentos_direitoshumanos.php>. Acesso em: 8 dez. 2013.

FERREIRA, J.R. A nova LDB e as necessidades educativas especiais. Caderno CEDES, Campinas, v. 19, n. 46, 1998.

FIGUEIRA, E. A presença da pessoa com deficiência visual nas Artes V. Rede SACI, São Paulo-SP, 2003.

GIL, M. (Org.). Deficiência visual. Brasília: Ministério da Educação, 2000.

JANNUZZI, G. A luta pela educação do deficiente mental no Brasil. 2 ed. Campinas: Editores Associados, 1992.

LIMA, F. J. \& SILVA, J. A. O desenho em relevo: uma caneta que faz pontos. Submetido em Terça, 27 dez. 2005 - por Lerparaver. Universidade de São Paulo - em Ribeirão Preto, São Paulo.

MAZZOTTA, M. J. S. Educação especial no Brasil: história e políticas públicas. São Paulo: Cortez, 1996.

MEDEIROS, A.; MEDEIROS, C. F. Possibilidades e limitações das simulações Computacionais no Ensino da física. Revista Brasileira de Ensino de Física, São Carlos, v. 24, n. 2, p. 32-45, 2002.

MENDES, E. G. Deficiência mental: a construção científica de um conceito e a realidade educacional. Tese de Doutorado. Universidade de São Paulo. São Paulo, 1995.

MIRANDA, A. A. B. Educação especial no Brasil: desenvolvimento histórico. Cadernos de História da Educação, n. 7, jan./dez. 2008

OCHAITA, E. \& ROSA, A. Psicología de la ceguera. Madrid: Alianza, 1993.

OCHAITA, E. \& ROSA, A. Percepção, ação e conhecimento em crianças cegas. Em C. Coll, J. Palacios \& A. Marchesi (Orgs), Desenvolvimento psicológico e educação: necessidades educativas especiais e aprendizagem escolar (p. 185-197). Porto Alegre: Artes Médicas, 1995.

OLIVEIRA, F. I. W. A importância dos recursos didáticos no processo de inclusão de alunos com necessidades especiais. In: GARCIA, W.G.; GUEDES, A.M.. (Org.). Núcleos de Ensino. 1 ed. São Paulo: FUNDUNESP, 
2003, v. 1, p. 21-24. Disponível em: <http://www.unesp.br/prograd/PDFNE2002/aimportanciadosrecdidaticos. pdf $>$. Acesso em 08 dez. 2013.

ORLANDO, T. C. et al. Planejamento, montagem e aplicação de modelos didáticos para abordagem de Biologia Celular e Molecular no Ensino Médio por graduandos de Ciências Biológicas. Revista Brasileira de Ensino de Bioquímica e Biologia Molecular, n. 1, fev. 2009.

ORMELEZZI, Eliana Maria. Os caminhos da aquisição do conhecimento e a cegueira: Do universo do corpo ao universo simbólico. 2000. 273 p. (Dissertação de Mestrado) Faculdade de Educação da USP, São Paulo.

RADABAUGH, M. P. Technology for access and function - Disponível em: <http://www.ncddr.org/new/ announcements/lrp/fy1999-2003/lrp_techaf.html> e <http://www.ncd.gov/ newsroom/publications/1993/ assistive.htm\#5>. Acesso em: 8 dez. 2013.

RIBEIRO, M. T. S. O educador frente a educação de pessoas cegas: enfocando as metodologias de alfabetização e inclusão social. 2001. 69 p. (Trabalho de Conclusão de Curso Pedagogia) Centro de Ciências Humanas e Educação da UNAMA, Universidade da Amazônia. Belém, Unamá.

RIBEIRO, Maria Tereza Soares. O educador frente a educação de pessoas cegas: enfocando as metodologias de alfabetização e inclusão social. 2001. 69 p. (Trabalho de Conclusão de Curso Pedagogia) Centro de Ciências Humanas e Educação da UNAMA, Universidade da Amazônia. Belém, Unamá.

RODRIGUES, D. Inclusão e Educação: doze olhares sobre a Educação Inclusiva (org.), São Paulo. Summus Editorial. 2006.

SÁ, E. D.; CAMPOS, I. M.; SILVA, M. B. C. Inclusão escolar de alunos cegos e com baixa visão. MEC, 2007. Disponível em: $\leq$ http://portal.mec.gov.br/seesp/arquivos/pdf/aee_dv.pdf $>$. Acessado em: 8 dez. $2013 .$.

SÁNCHEZ, P. A. A educação inclusiva: um meio de construir escolas para todos no século XXI.INCLUSÃO - Revista da Educação Especial - Out/2005. p. 07 a 18. Disponível em: http://www.rsacessivel.rs.gov.br/ uploads/1236187705revistainclusao1.pdf\#page=7 . Acessado em: $08 \mathrm{dez} 2013$.

SCHNEIDER, M. B. D. Subsídios para a ação pedagógica no cotidiano escolar inclusivo, nov. de 2003. Disponível em: $\leq$ http://www.adefib.org.br/artigo $>$. Acesso em: 8 dez. 2013..

SGARABOTTO, A. L.; DURANTI, R. R. T. Aprendizagem em Geografia por adolescentes com deficiência visual em uma escola Estadual. Universidade de Caxias do Sul (UCS), 2006.

SOARES, Maria Rosana; PAULINO, Paulo Cesar. História e Tendências da Educação Inclusiva. III Curso de Especialização em Educação Profissional. Universidade Tecnológica Federal do Paraná, 2009.

WILSON, J. “Doing justice to Inclusion”; European Journal of Special Needs Education, v. 15, n. 3, p. 297304, 2002.

ZABALA, Antonio. A Prática Educativa: Como ensinar. (resenha). Ed. Porto Alegre, Artes Médicas, 1998. 7 p. 